Proc. Estonian Acad. Sci. Eng., 2006, 12, 1, 59-71

\title{
Modelling of thermal processes in apartment houses
}

\author{
Sven Peets, Tõnis Peets and Eugen Kokin \\ Institute of Engineering, Estonian University of Life Sciences, Fr. R. Kreutzwaldi 56, 51014 Tartu, \\ Estonia; psven@eau.ee \\ Received 1 October 2004, in revised form 1 November 2005 \\ Abstract. The objective of this paper is to explore dynamic thermal processes of apartment houses \\ and to investigate the possibilities of energy saving. The building has been divided into a set of \\ individual rooms. A dynamic model of heat-exchange of a single flat and of a part of the house has \\ been created in MatLab Simulink environment. Influence of the switching off the heating in a \\ middle apartment to the temperature in the house has been investigated.
}

Key words: heat transfer, energy saving, temperature, energy losses, heat flows.

\section{INTRODUCTION}

Saving energy has been a priority in Europe since the first oil crisis in 1973. Maintaining the quality of the environment, ensuring rational use of resources, reducing air pollution and promoting the improvement of the energy performance of buildings $\left[{ }^{1,2}\right]$ is most vital also for Estonian energy strategy $\left[{ }^{3}\right]$. The majority of the apartment houses in Estonia were built in the second half of the last century when heating energy was cheap and quality of materials and work was low. These buildings have high heat energy losses and therefore correspondingly large energy saving potential $\left[{ }^{4,5}\right]$. The aim of this paper is to explore dynamic thermal processes of apartment houses and to investigate the possibilities of energy saving.

Thermal behaviour of buildings has been studied by different methods. Temperature control system for a building was modelled in $\left[{ }^{6}\right]$. Block diagram of the heat balance of a building and a model of the heating system was created with the help of MatLab. Assumption that all the rooms in the building are connected with each other, so that the air is moving freely inside the building, was made. 
The model was refined in $\left[^{7}\right]$. The results of the modelling were very close to the measurement results in a real building.

Further development of the model is suggested by dividing the building into a set of individual rooms. IDA Indoor Climate and Energy $\left[{ }^{8}\right]$ is a new generation simulator of the whole building, allowing simulation of the dynamic heat balance of multiple zones, solar influx through windows, air and surface temperatures, $\mathrm{CO}_{2}$ and moisture levels, and wind buoyancy driven airflows through leaks and openings via a fully integrated airflow network model. DOE- $2\left[{ }^{9}\right]$ is a building simulation program that performs hourly simulation of the energy consumption and energy cost of a building, given a description of the climate, architecture, materials, operating schedules and heating, ventilation and air conditioning (HVAC) equipment of the building. TRNSYS $\left[{ }^{9}\right]$ is used primarily to simulate thermal energy systems - solar systems and general HVAC systems. SPARK $\left[{ }^{10}\right]$ is a modular environment that automates writing code for systems of non-linear equations. EnergyPlus $\left[{ }^{11}\right]$ combines best features of BLAST and DOE-2, and includes a number of innovative simulation features as: variable time steps and user-configurable modular systems that are integrated with the heat and mass balance-based zone simulation.

\section{DESCRIPTION OF THE PROBLEM}

The energy strategy $\left[{ }^{1-3}\right]$ requires actions in areas such as individual metering and billing of energy use, energy audits and certification of buildings. Individual heat energy measurement motivates inhabitants to save energy opposite to prevalent scheme where the consumed heat energy is divided according to the floor area of the flat. In the latter case the energy consumption of the whole house is measured and not the actual energy consumption of every flat. The individual heat energy measurement is good but its disadvantage is that flats are thermally connected with each other through adjacent walls; if one flat is not heated and its room temperature is lower then ambient flats start to heat the colder one. As a result, the heat energy consumption of ambient flats increases to keep the same room temperature. The described situation can arise if one flat tries to save energy by reducing the heating power and lowering the room temperature or if it is separated from the common heat supply system of the building. The heat energy demand of a flat depends also on the location of the flat in the building, e.g. endmost and upper floor flats have bigger heat demand than flats located in the middle of the building, because they have more outer walls. Therefore it is necessary to study heat flows between flats in the building under various conditions. Definitely there are more than one model or building simulation programs that meet the requirements. Since we are dealing with a specific problem, we develop further the model described in $\left[^{7}\right]$. 


\section{HEAT-EXCHANGE PROCESSES IN THE BUILDING}

The object of the investigation is a typical 5-floor apartment house for which we have necessary data. Given house is built in 1982, has two staircases, 30 apartments and total heated area $1584 \mathrm{~m}^{2}$. Outer dimensions are the following: length 35.4 , width 11.75 and height $15.5 \mathrm{~m}$; complete description is given in [ $\left.{ }^{4,5}\right]$. For studying heat flows, the building is divided into units - flats and staircases. We use two-sign marking of the elements so that the first sign $(A, \ldots, H)$ indicates function of the element and its placement in the ground plan and the second sign $(1, \ldots, 5)$ indicates the floor. Letters $A, B, C, D, E$ and $F$ indicate flats, and $G$ and $H$ staircases (Fig. 1).

The model is composed of nine flats: $A 2, B 2, C 2, A 3, B 3, C 3, A 4, B 4$ and $C 4$. Using the chosen flats it is possible to study most of the situations we are interested in and this set of flats is sufficient for making general conclusions. In case of the current set, the flat $B 3$ is surrounded from every side with other flats that also belong to the model. In that case we can investigate all heat flows going in and out from the flat $B 3$. The flats of the 1 st and 5th floor are thermally in a different situation. That can be taken into account by changing parameters of the apartments on the 2nd and 4th floor. We can also add additional layers to walls and change heat transmission coefficients.

We start the analysis by calculating the heat balance of a single flat. First we have to distinguish the bodies that are involved in heat transfer. As the real object is too complex, it is impossible to distinguish and describe mathematically all existing heat flows. Thus several simplifications have to be made. Assuming that doors between rooms are open, we consider the flat as a single room where the air is moving freely. Inner walls and furniture are considered as inner objects that accumulate thermal energy; there is no heat loss through them. Outer bounds of the apartment are divided into separate groups in order to study heat loss to outside air and heat flows between separate flats. Ventilation heat loss is also included. The temperature of the inner air is considered to be homogeneous within the flat. In addition to the heating power, inner heat sources are taken into

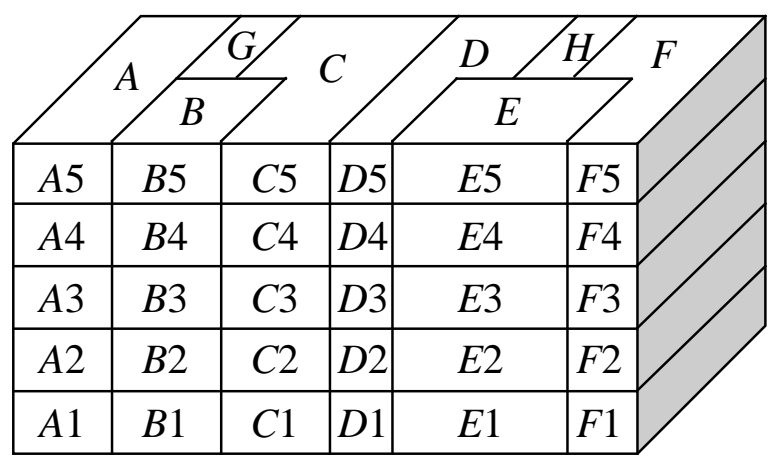

Fig. 1. Marking of the apartments in the house. 
account: heat flow from people to the inner air and heat flow from hot water pipes, electric and gas-stows and baths.

Substitutional diagram of heat exchange for the flat $B 3$ is shown in Fig. 2. The flat is adjacent to four apartments and a staircase. Heat is transferred to ambient air through their elements. The substitutional diagrams of these elements are summarized in blocks $G, B 2, B 4, A 3$ and $C 3$.

On the basis of the substitutional diagram it is possible to compose differential equations for the heat balance $\left[^{5}\right]$. The equation may be written in a generalized form for each body of the system as

$$
C_{i} \frac{\mathrm{d} T_{i}}{\mathrm{~d} t}=Q_{i}=\sum_{j=1}^{n} Q_{i, j}
$$

where $C_{i}$ is heat capacitance of the body $i(\mathrm{~J} / \mathrm{K}), T_{i}$ is average temperature of the body $i\left({ }^{\circ} \mathrm{C}\right), Q_{i}$ is heat flow saved in the body $i(\mathrm{~W}), Q_{i, j}$ is heat flow

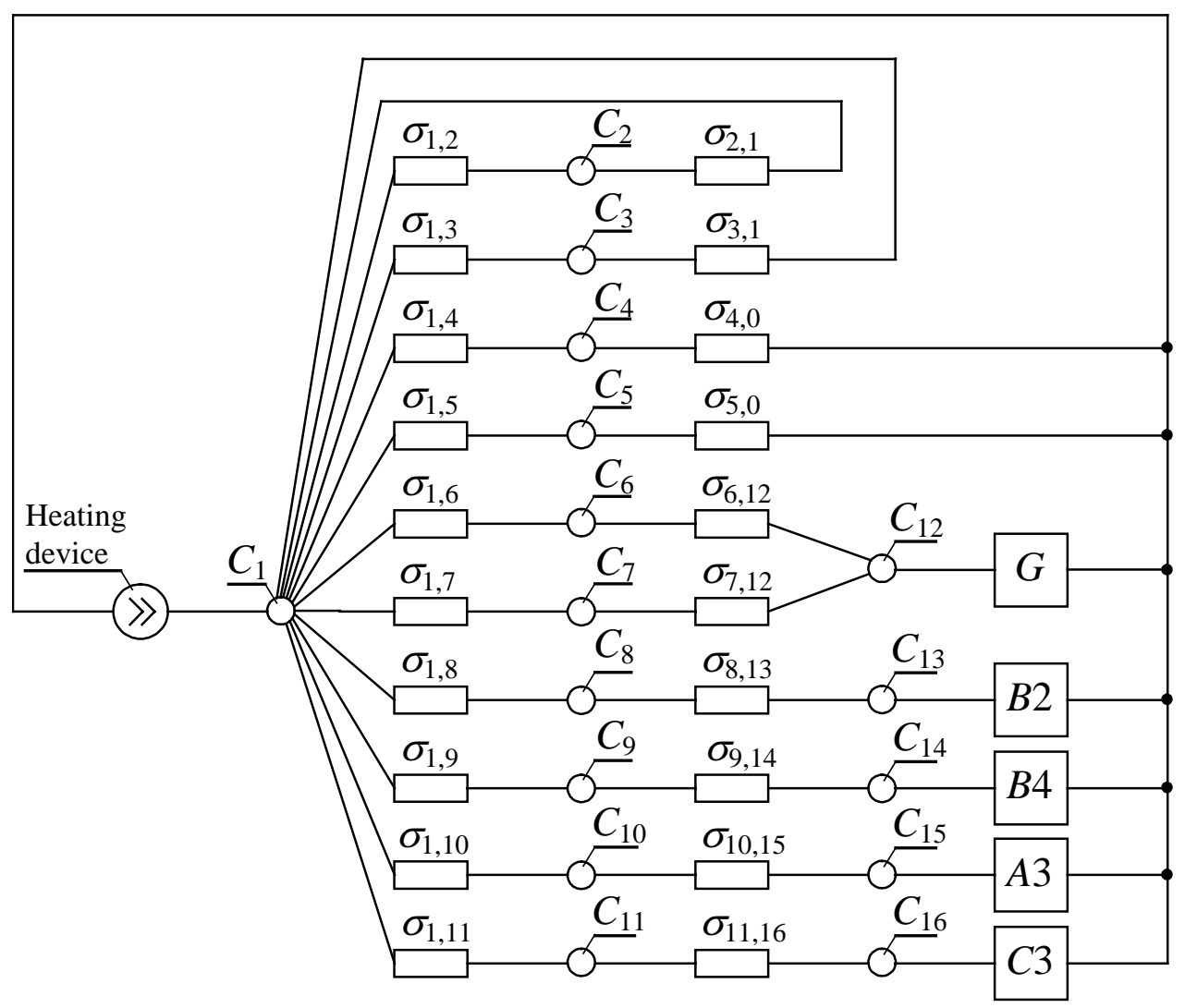

Fig. 2. Substitutional diagram of heat exchange for flat B3: $C_{1}$-inner air, $C_{2}$-inner walls, $C_{3}$ - furniture, $C_{4}$ - outside walls, $C_{5}$ - window, $C_{6}$ - door to the staircase, $C_{7}$ - wall between the flat and staircase $G, C_{8}$ - floor, $C_{9}-$ ceiling, $C_{10}-$ wall $A 3, C_{11}-$ wall $C 3, C_{12}-$ air $G, C_{13}-$ air $B 2$, $C_{14}-\operatorname{air} B 4, C_{15}-$ air $A 3, C_{16}$ - air $C 3, \sigma$ - thermal conductivity between bodies. 
between bodies $i$ and $j(\mathrm{~W}), j$ is sequential number of the body involved in heat exchange with body $i$ and $n$ is the number of bodies involved in heat exchange with the body $i$.

Heat flow between bodies $i$ and $j$ may be expressed as

$$
Q_{i, j}=\sigma_{i, j}\left(T_{i}-T_{j}\right)
$$

Here $\sigma_{i, j}$ is heat conductance between bodies $i$ and $j(\mathrm{~W} / \mathrm{K})$ :

$$
\sigma_{i, j}=K_{i, j} S_{i}
$$

where $K_{i, j}$ is the heat transmission coefficient $\left(\mathrm{W} /\left(\mathrm{m}^{2} \cdot \mathrm{K}\right)\right)$ and $S_{i}$ is surface area of the body $i$ involved in heat exchange $\left(\mathrm{m}^{2}\right)$.

Heat capacitance of a body may be found using the equation

$$
C_{i}=\sum_{k=1}^{m} c_{k} \rho_{k} V_{k},
$$

where $k$ is the sequential number of the layer of the body, $m$ is the number of layers, $c_{k}$ is specific heat of the material $(\mathrm{J} /(\mathrm{kg} \cdot \mathrm{K})), \rho_{k}$ is density $\left(\mathrm{kg} / \mathrm{m}^{3}\right)$ and $V_{k}$ is volume $\left(\mathrm{m}^{3}\right)$.

\section{DYNAMIC HEAT-EXCHANGE MODEL OF THE HOUSE}

On the basis of heat balance equations it is possible to compose the Simulink block diagram of the house consisting of nine apartments. Figure 3 shows the block diagram of the inner walls for the apartment $B 3$, where the input is inner air temperature $T_{1}$ and output is the temperature of the inner wall $T_{2}$ and heat flow between inner air and inner walls is $Q_{1,2}$. Heat exchange block diagram for furniture is similar.

Inputs of the block diagram of outside walls (Fig. 4) are ambient temperature $T_{0}$ and inner air temperature $T_{1}$. Outputs are temperature of the outside walls $T_{4}$, heat flow between inner air and outside walls $Q_{1,4}$, heat flow saved in outside walls $Q_{4}$ and heat flow between outside walls and ambient air $Q_{4,0}$. Blocks for heat exchange with ambient environment are similar.

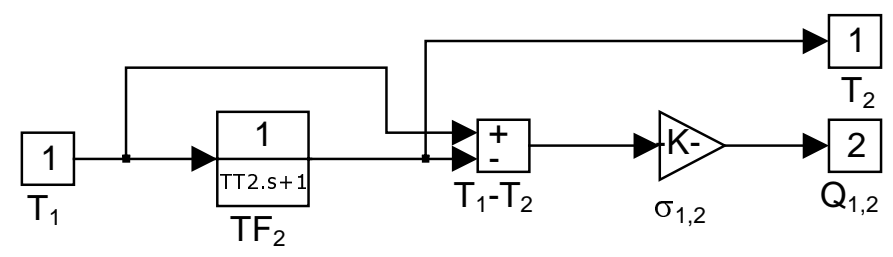

Fig. 3. Block diagram of inner walls. 


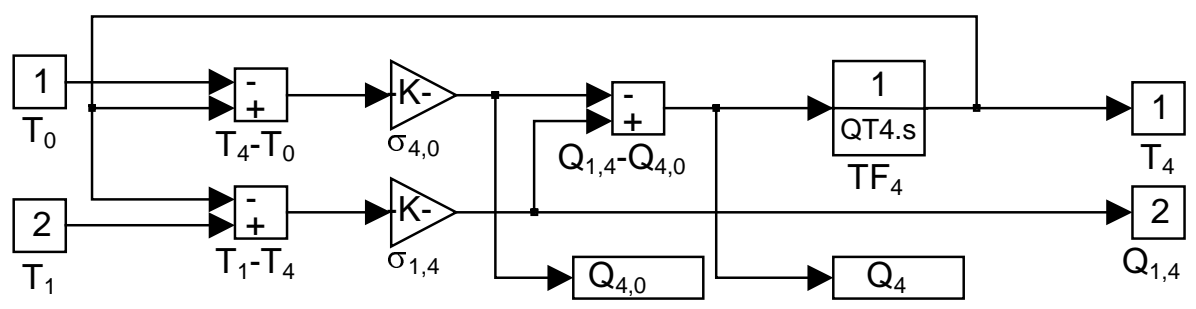

Fig. 4. Block diagram of outside walls.

Inputs of the block diagram of the heat balance of an apartment (Fig. 5) are heat flow from the heating device, ventilation rate and temperatures of the ambient air, staircase and adjacent apartments. Outputs are temperatures and heat flows of the bodies. To simplify the schema, block diagrams of different bodies are summarized in sub-blocks. Heat balance block diagram of the house (Fig. 6) consists of sub-blocks of the apartments and connections between them.

The model is applicable only if all parameters, coefficients and functions are determined. They are given in $\left[^{5}\right]$.

To control the temperature of the inner air we use a PID-controller (Fig. 7) and determine the parameters using the Ziegler-Nichols method. Electrical heaters are used in the heating system and the maximum heating power is limited.

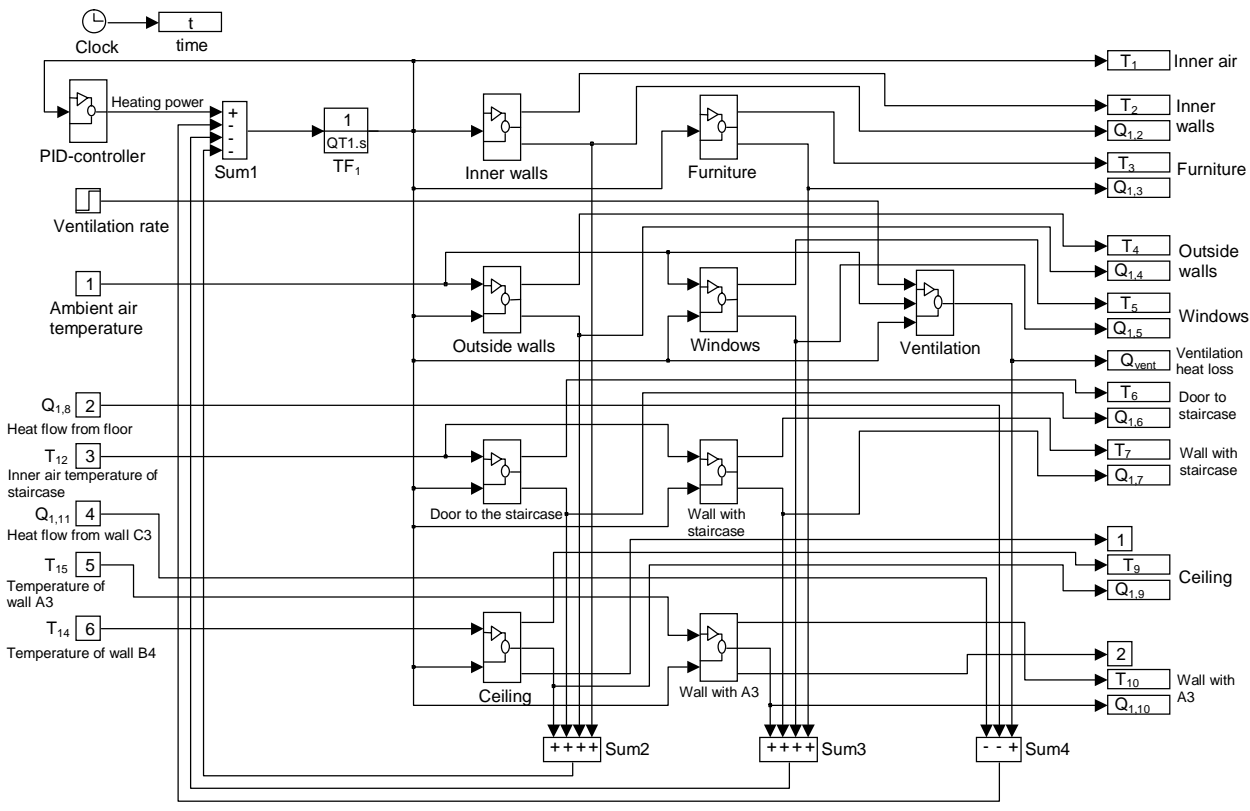

Fig. 5. Heat balance block diagram for the apartment $B 3$ in Simulink. 


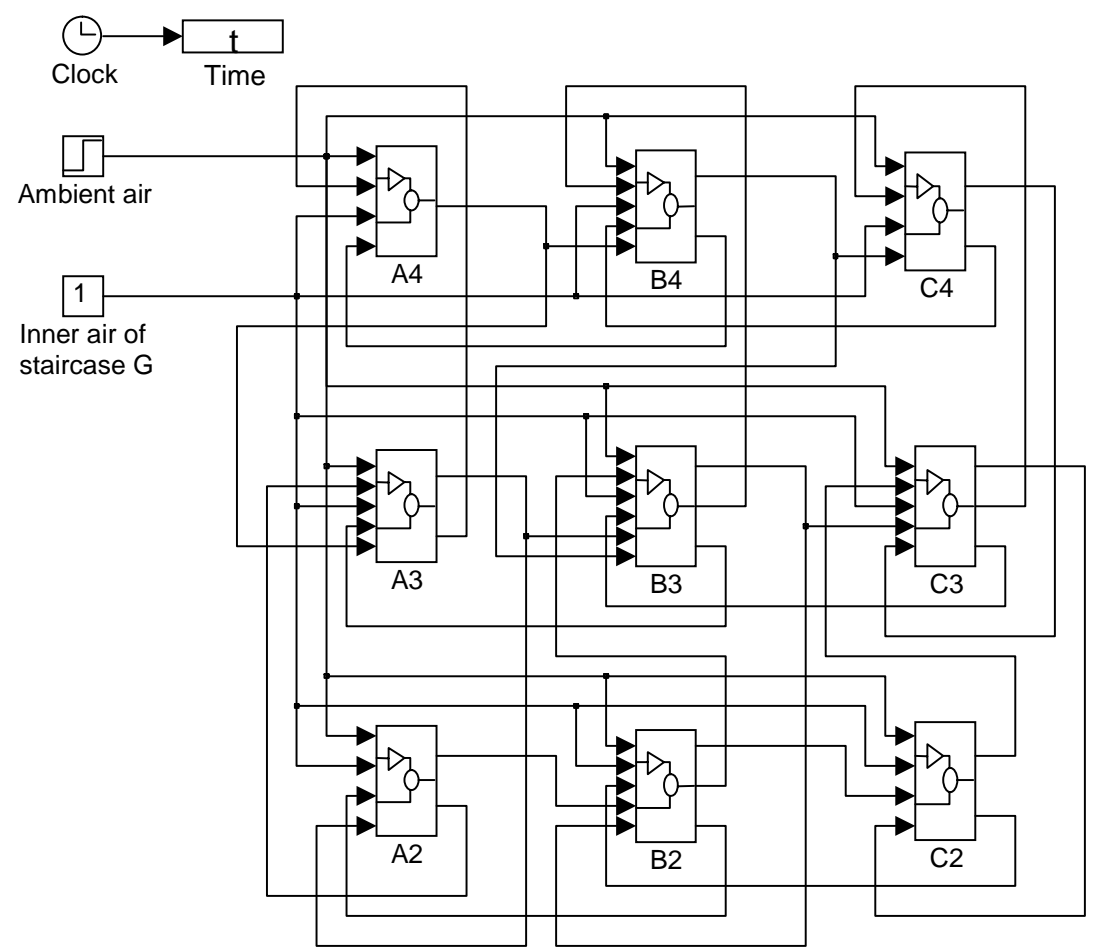

Fig. 6. Heat balance block diagram for a part of the house.

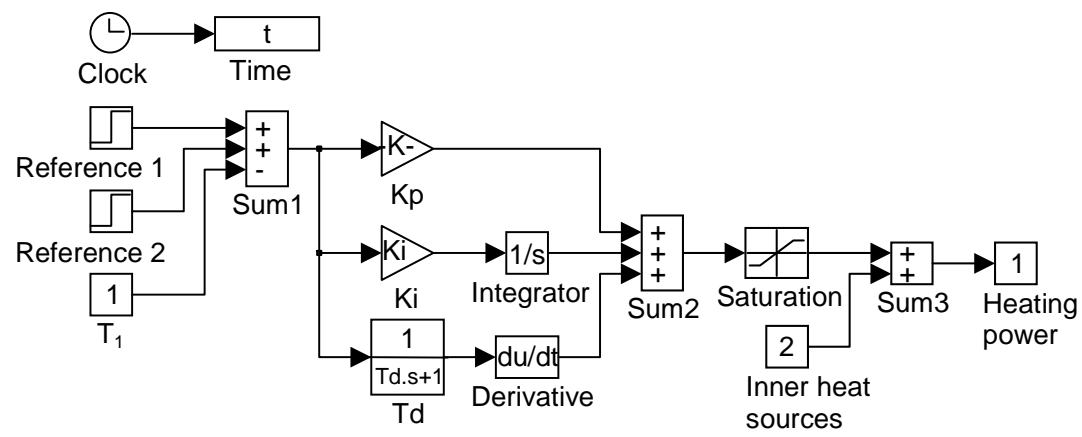

Fig. 7. PID-controller for inner air.

\section{MODELLING RESULTS}

Simulating the response of the inner air temperature it is possible to study the speed of temperature change of the inner air and other bodies in the house (Fig. 8). Reference value is changed after stabilization, which takes 100 hours. In the beginning of the experiment all temperatures are at zero. Shown results 


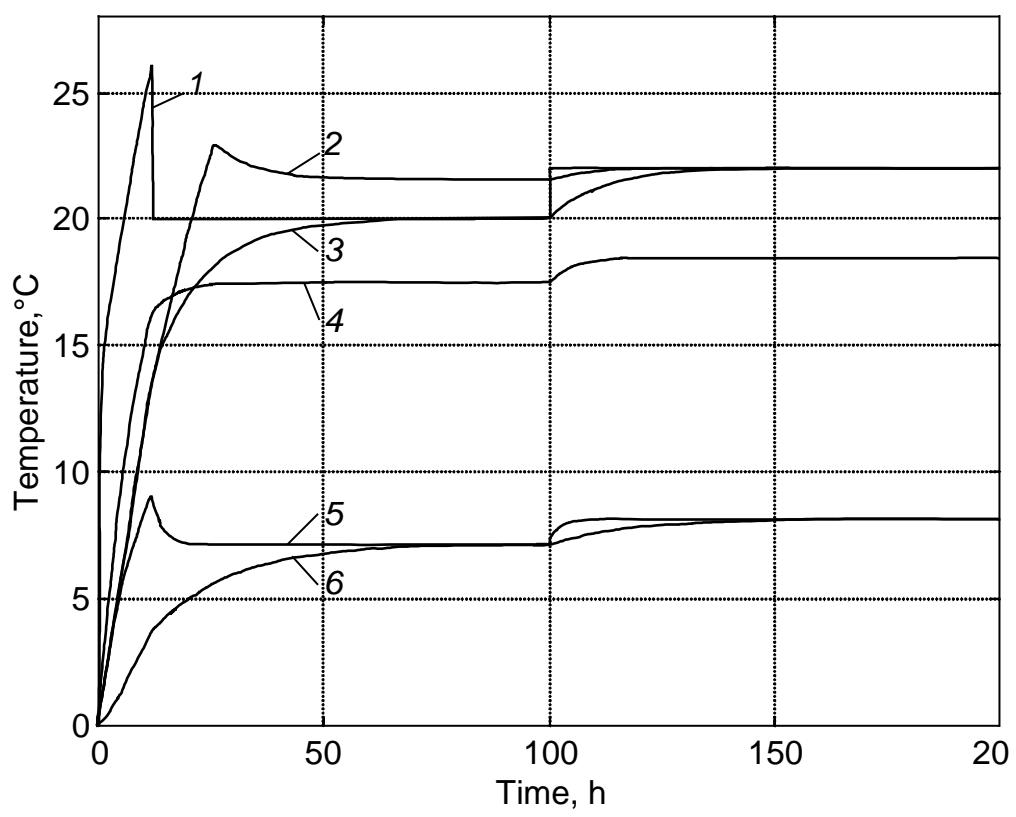

Fig. 8. Variation of the temperature of the inner air (1), floor (2), inner walls (3), staircases wall (4), windows (5) and outside walls (6) in apartment $B 3$ at steady ambient temperature of $-5^{\circ} \mathrm{C}$.

describe the situation where ventilation rate is normal $\left.\left(0.7 \mathrm{l} /\left(\mathrm{s} \cdot \mathrm{m}^{2}\right)\right){ }^{12}\right]$ and inner temperatures of adjacent apartments are also normal $\left(+22^{\circ} \mathrm{C}\right)\left[{ }^{12}\right]$. It appears that there is overshoot of the inner temperature in the beginning of the experiment, but this is a hypothetical situation where all temperatures start at zero. The control accuracy is sufficient in case of increasing the reference temperature by $2{ }^{\circ} \mathrm{C}$ after stabilization.

Thermal influence of a single flat on adjacent flats is interesting if the heating power of a single flat is turned off and the inner air temperature starts to decrease. The case when heating is switched off in apartment $B 3$ is modelled. Initial inner air temperature was $+22^{\circ} \mathrm{C}$. After switching off the heating, the inner air temperature in apartment $B 3$ decreases to $+18.2^{\circ} \mathrm{C}$ (Fig. 9). Heat flows from adjacent apartments (Fig. 10) increase with resulting increase of the heating power to maintain the same inner air temperature.

From Table 1 we see that although the heating power of the apartment $B 3$ decreases by $1071 \mathrm{~W}$, the total heating power of adjacent apartments increases by $811 \mathrm{~W}$ to maintain the same room temperature there. Thus the actual decrease of the heating power is only $260 \mathrm{~W}(-3.03 \%)$ because apartments are thermally connected with each other and the heat flow is redistributed internally in the house. In case of reducing the inner air temperature by $2{ }^{\circ} \mathrm{C}$ in the same conditions in apartment $B 3$, the heating power decreases to $507 \mathrm{~W}$ in $B 3$ and the total heating power change is $-136 \mathrm{~W}(-1.61 \%)$. Thus based on modelling results, switching off heating in one middle apartment saves energy $3.03 \%$ in 


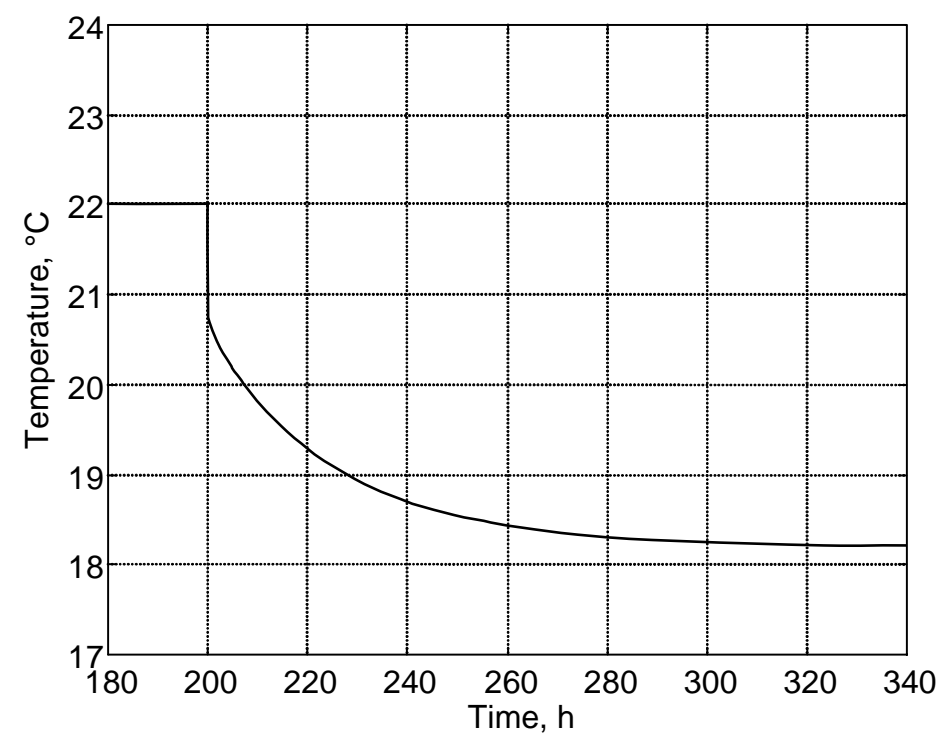

Fig. 9. Variation of the inner air temperature in apartment $B 3$ after switching off the heating at ambient temperature $-5^{\circ} \mathrm{C}$.

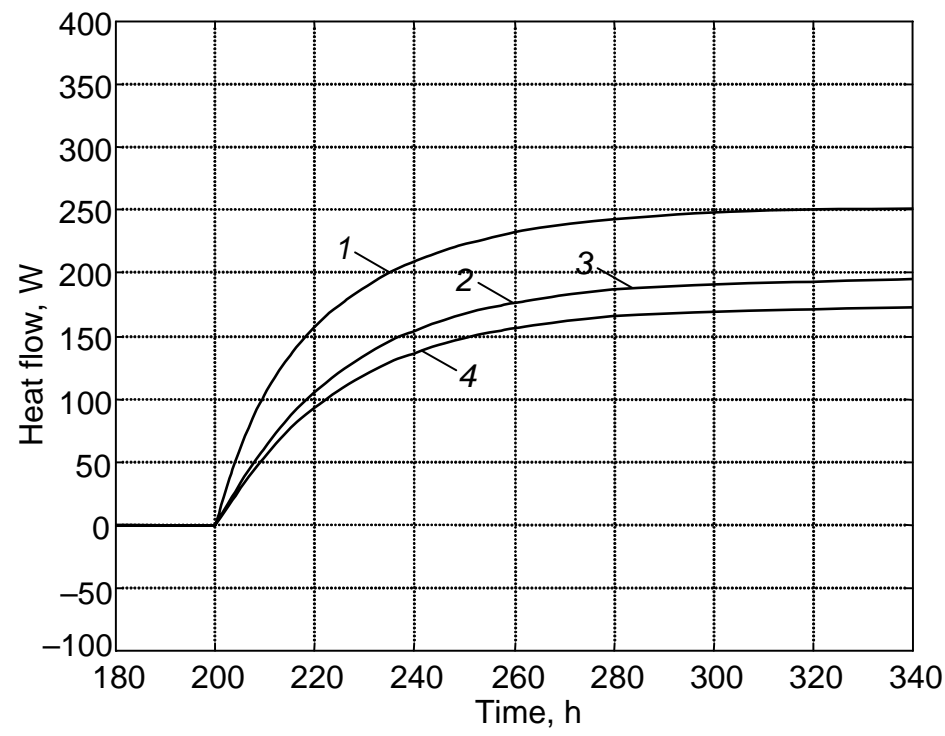

Fig. 10. Variation of the heat flows from adjacent apartments to $B 3$ after switching off the heating in apartment B3: 1 - wall C3, 2 - ceiling, 3 - floor and 4 - wall A3.

total despite the redistribution of heat flows in the building and of the increase of the heating power in neighbouring apartments. Similarly the case when two or more apartments switch off the heating can be studied. 
Table 1. The change of heating power in case of turning off the heating in apartment $B 3$

\begin{tabular}{lcccc}
\hline Apartment & Heating power, $\mathrm{W}$ & Change, $\mathrm{W}$ & Change, $\%$ \\
\hline$B 3$ & 1071 & -1071 & -100 \\
$B 2$ & 1123 & +195 & +17.4 \\
$B 4$ & 1123 & +195 & +17.4 \\
$A 3$ & 2708 & +171 & +6.32 \\
$C 3$ & 2562 & +250 & +9.76 \\
Total & 8587 & -260 & -3.03
\end{tabular}

Figure 11 shows the dependence of the heating power on the inner air temperature in the steady state situation. We may conclude that increasing or decreasing the inner air temperature by $1{ }^{\circ} \mathrm{C}$ leads to the heating power change of about $5 \%$. Thus avoiding overheating by $1{ }^{\circ} \mathrm{C}$ saves energy about $5 \%$.

Specific heating power of apartments is shown in Fig. 12 for the case when the inner air temperature is $+22^{\circ} \mathrm{C}$, ventilation rate is normal and ambient air temperature is $-7^{\circ} \mathrm{C}$. We see that apartments of the group $B$ have the smallest specific heating power; group $C$ needs somewhat higher heating power, because the area of the outside walls is larger. End apartments (group $A$ ) have the highest heat energy loss. Average specific heating power is $45.6 \mathrm{~W} / \mathrm{m}^{2}$ and actual measured specific heating power is $49.9 \mathrm{~W} / \mathrm{m}^{2}\left[{ }^{4,7}\right]$ (the difference is $8.6 \%$ ).

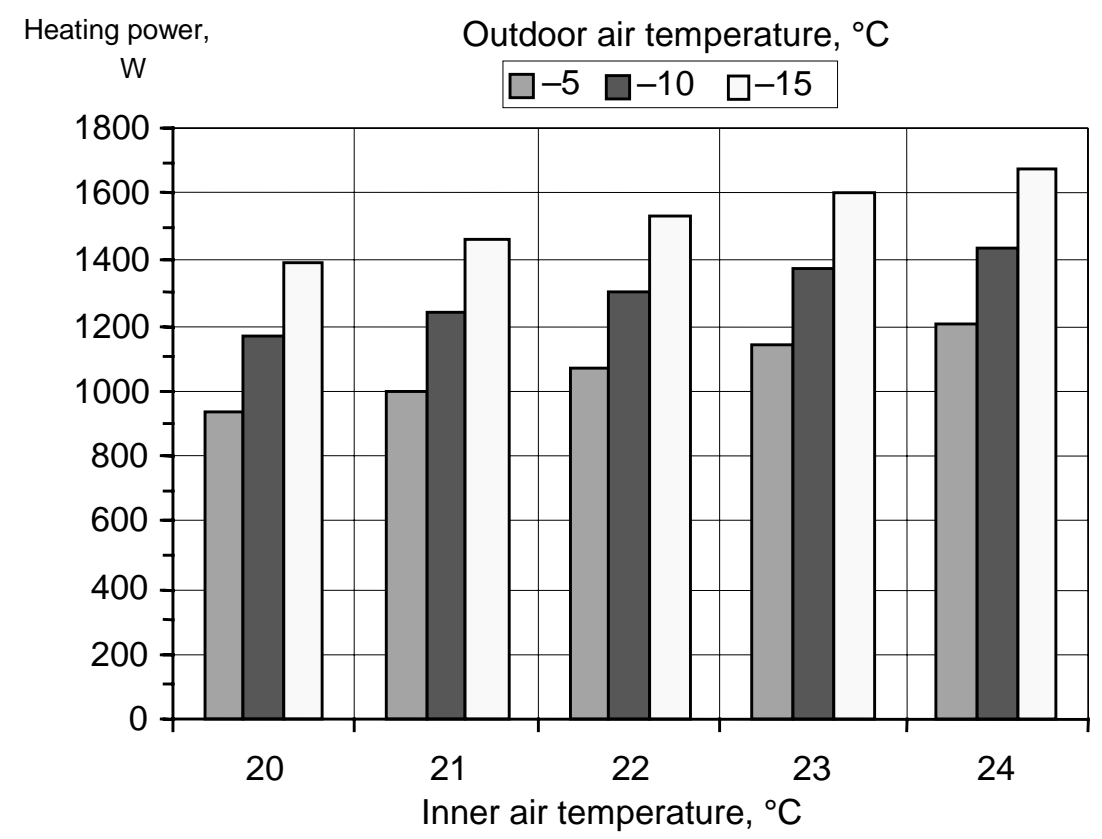

Fig. 11. Heating power of apartment $B 3$ at different inner and ambient temperatures. 


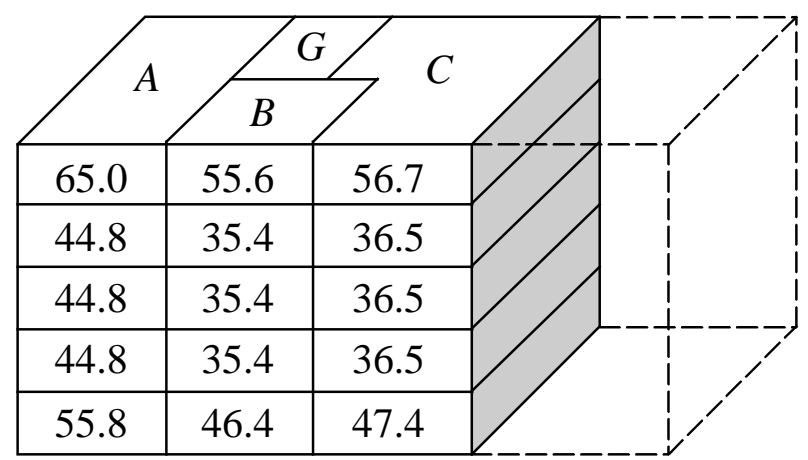

Fig. 12. Specific heating power of the apartments, W/m $\mathrm{m}^{2}$.
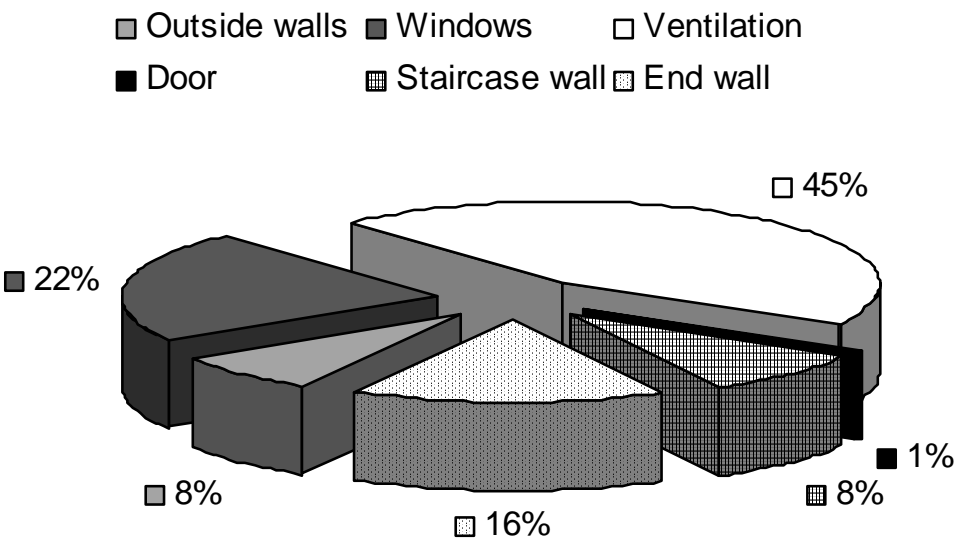

Fig. 13. Heat balance of the apartment $A 3$.

Heat balance of the apartment $A 3$ is presented in Fig. 13. The biggest heat energy loss is caused by ventilation, through windows and end walls. Energy conservation potential is in the insulation of the envelope of the building, especially of the end walls and roof. It decreases inequality in individual costs.

\section{SUMMARY}

The purpose of this paper was to explore dynamic thermal processes of an apartment house and to ascertain the possibilities of energy saving. The heatexchange dynamic model of the apartment house was created and it helps us to study the change of temperatures and heat flows in the house. 
After decreasing the heating power by $1071 \mathrm{~W}$ in an apartment, which is situated in the middle of the house, the inner air temperature decreases from 22 to $18.2^{\circ} \mathrm{C}$. The actual decrease of the heating power is $260 \mathrm{~W}$ because apartments are thermally connected with each other and the heat flow is redistributed internally in the house. Energy saving is $3.03 \%$ in that case. Average specific heating power, resulting from the model, is close to the actual measured specific heating power (difference in 8.6\%). Insulation of the envelope of the building saves energy and decreases inequality in individual costs.

Suggested methods can supplement energy auditing of buildings if all necessary input data is present and detailed analysis of a building is needed. The results of the work may be useful for housing associations, designers, managers of apartment houses and others to solve problems related to thermal energetics.

\section{REFERENCES}

1. Council Directive 93/76/EEC of 13 September 1993 to limit carbon dioxide emissions by improving energy efficiency (SAVE). Official Journal, L237, 22/09/1993, 0028-0030.

2. Directive 2002/91/EC of the European Parliament and of the Council of 16 December 2002 on the energy performance of buildings. Official Journal, L001, 04/01/2003, 0065-0071.

3. Kütuse- ja energiamajanduse pikaajalise riikliku arengukava aastani 2015 kinnitamine. Riigi Teataja, 2004, No. 88, I.

4. Peets, T., Kokin, E. and Peets, S. Analysis of the house thermal energetics. In Agricultural Machinery, Building and Energy Engineering (Liiske, M. et al., eds.). Estonian Agricultural University Trans., Tartu, 2000, No. 206, 127-135.

5. Peets, S. Research of Thermal Energetics of an Apartment House. Master Thesis. Estonian Agricultural University, Tartu, 2002.

6. Kokin, E. and Liiske, M. Modelling of temperature control system for a building with districtheating supply. In Agricultural Machinery and Energy Engineering (Heinloo, M. et al., eds.). Estonian Agricultural University Trans., Tartu, 1996, No. 189, 53-61.

7. Kokin, E., Liiske, M. and Peets, T. Modelling of the heating system for a building. In Agricultural Machinery, Building and Energy Engineering (Liiske, M. et al., eds.). Estonian Agricultural University Trans., Tartu, 2000, No. 206, 62-70.

8. Sahlin, P., Eriksson, L., Grozman, P., Johnsson, H., Shapovalov, A. and Vuolle, M. Wholebuilding simulation with symbolic DAE equations and general purpose solvers. Build. Environ., 2004, 39, 949-958.

9. Hong, T., Chou, S. K. and Bong, T. Y. Building simulation: an overview of developments and information sources. Build. Environ., 2000, 35, 347-361.

10. Musy, M., Winkelmann, F., Wurtz, E. and Sergent, A. Automatically generated zonal models for building air flow simulation: principles and applications. Build. Environ., 2002, 37, 873-881.

11. Crawley, D. B., Lawrie, L. K., Winkelmann, F. C., Buhl, W. F., Huang, Y. J., Pedersen, C. O., Strand, R. K., Liesen, R. J., Fisher, D. E., Witte, M. J. and Glazer, J. EnergyPlus: creating a new-generation building energy simulation program. Energy Build., 2001, 33 , 319-331.

12. Eesti Standard EVS 839:2003. Sisekliima. Eesti Standardikeskus, Tallinn, 2003. 


\title{
Korterelamu soojusprotsesside modelleerimine
}

\author{
Sven Peets, Tõnis Peets ja Eugen Kokin
}

On koostatud 5-korruselise korterelamu osa dünaamiline mudel MatLabi keskkonnas, mis võimaldab uurida hoonesiseseid soojusvooge. On esitatud korteri soojuslike seoste skeem, soojusbilansi võrrandid, elamu osa ja selle alamosade mudel. On simuleeritud mitmesuguseid soojuslikke olukordi ja uuritud hoone temperatuuride ning soojusvoogude muutusi. 